\title{
“¿QUÉ NO SÉ DEL AMOR ..?” PARA UNA NUEVA LECTURA DE "LOS SONETOS DE LA MUERTE", DE GABRIELA MISTRAL
}

\author{
POR
}

\author{
GRínOR RoJo \\ California State University, Long Beach
}

De "Los sonetos de la muerte" se han dicho muchas cosas, algunas razonables y otras no tanto. Para no remontarnos muy atrás, recordemos que en 1957 Margot Arce de Vázquez le dio a un rumor que circulaba desde hacía ya algún tiempo ciertos visos de legitimidad al sugerir que en la sección "Dolor" de Desolación, donde "Los sonetos ..." se republicaron en la forma que hoy nos es familiar, aunque los poemas parezcan seguir el desarrollo de una sola historia, una lectura cuidadosa revela la presencia de otra. "El ruego", dictamina Arce de Vázquez, "cierra el ciclo de la primera; el 'Nocturno' expresa la crisis de la segunda". A lo que agrega: "si es cierto que los poemas de 'Dolor' se refieren a dos experiencias distintas, su disposición en un orden que nada tiene que ver con la secuencia de los hechos despista al lector y le hace creer que se trata de un amor único frustrado por el suicidio del amado. Los poemas 'Sonetos de la muerte', 'Interrogaciones', 'La obsesión', las 'Coplas' de la página 127 [este dato de Arce remite a la primera edición del libro], 'Ceras eternas', 'Volverlo a ver', 'La condena', 'El vaso', 'El ruego', 'Los huesos de los muertos' parecen referirse a aquel suceso doloroso. 'El amor que calla', 'Éxtasis', 'Íntima', 'Dios lo quiere', 'Desvelada', 'Vergüenza', 'Balada', 'Tribulación', 'Nocturno' y casi todos los poemas de la sección 'Naturaleza' parecen aludir al segundo amor, vivido algunos años después". 1

\footnotetext{
${ }^{1}$ Margot Arce de Vázquez. Gabriela Mistral: persona y poesía (San Juan de Puerto Rico: Asomante, 1957) 43-44. Por cierto, el gasto especulativo en torno a la base biográfica de "Los sonetos ..." da por sí solo para un relato aún más nutrido que el de "Los sonetos ..." mismos. Hasta donde a mí me es posible recapitularlo, empieza en los años veinte y no sin la colaboración de la poeta. Virgilio Figueroa le echa la culpa de su estreno al periodista ríoplatense Juan José de Soiza Reilly, quien el 17 de febrero de 1926 publicó en el Correo de Valdivia un artículo que se titulaba "El único amor de Gabriela Mistral" y donde se leía: "Un amor infinito. Terrible. Fogoso. Sangriento. Y puro. ¡Puro! Diré una vez la palabra que borrará el equívoco; un enorme amor puro por un hombre suicida ... un joven, muy triste, muy tímido, muy bueno. Desempeñaba en el ferrocarril un modesto cargo de guardatrén o estafetero. Y aquí viene lo triste ... Era un hombre común. Se emborrachaba gastando su sueldo en la cantina ... El doncel idealizado fue despedido de la empresa ferroviaria. Tuvo que ingresar en una tienda como modesto dependiente ... Un día, necesitado de dinero para satisfacer su vicio alcohólico, el muchacho extrajo de la caja del patrón un fajo de billetes de banco. Esa misma noche, ebrio y arrepentido de su acción, se pegó un tiro. El eco de aquel tiro es Gabriela Mistral". Alude también Figueroa a una conferencia y un artículo de 1933, ambos de David Rojas
} 
Más impetuosamente, el mismo año de la publicación del estudio de Arce, Gastón von dem Bussche comparó a la hablante de "Los sonetos ..." con la Catherine Earnshaw de Wuthering Heights y vio en ambas mujeres a las propietarias de unas "almas" cuyo "gran pecado" es el "haber enloquecido en su afán de trascendencia amenazada. Frenéticas en la avidez de una celosa posesión", exclama von dem Bussche, "han preferido la victoria de una rival distinta de todas: la muerte, para evitar el sacrilegio de la traición". ${ }^{2}$ Al enfrentarse con el primero de "Los sonetos ...", Jorge Guzmán desenfunda por su parte, y con no menos ímpetu que von dem Bussche, la teoría de que "el traslado del cadáver, desde el nicho a la tierra, es una operación mítica, en virtud de la cual un hombre muerto vuelve a ser niño, y la 'yo' que celebró su muerte movida por los celos es quien lo ha originado, engendrado y parido, sola. El destino normal de una enamorada, pues, que habría engendrado un hijo con el amado, se cumple aquí por la vía simbólica y virginal; ella lo vuelve al seno de la tierra y obtiene, por transformación del cadáver, un niño". ${ }^{3}$

González, contemporáneo de la poeta, y a una carta que ese mismo año le envía a él "una diligente y distinguida profesora de La Serena", todo ello abundante en detalles reveladores. Por último, él mismo se expresa así: "un martirio de amor envuelve la nubilidad de la poetisa. Es su primero y su único amor ... Ella no ha descorrido el velo de esa pasión, pero en sus versos aparece a cada instante. Es la orquesta que preludia sus 'Sonetos de la muerte' ... como el amor trae dudas y recelos, ella piensa que su amado puede faltarle a la fe jurada, $y$, entonces, ante esta idea que crispa sus nervios, le dice en frases erizadas y candentes: 'La tierra se hará madrastra, si tu alma vende a mi alma; Dios no quiere que tú tengas sol, si conmigo no marchas; Dios no quiere que tú bebas, si yo no tiemblo en tu agua, y si te vas y mueres lejos, tendrás la mano ahuecada diez años bajo la tierra para recibir mis lágrimas'. El presagio se realizó y 'malas manos entraron trágicamente en él', y ella, que no le puede gritar, ni le puede seguir, 'le pide al Señor que lo retorne a sus brazos o le siegue en flor". Virgilio Figueroa. La divina Gabriela (Santiago de Chile: El Esfuerzo, 1933) 76-82. En una cuerda similar se manifiesta Julio Saavedra Molina, quien en sus trabajos que van desde 1937 a 1958 , los que dicho sea en honor de la verdad son un solo trabajo, reconstruye el acontecer personal de Gabriela desde los poemas de Desolación, $y$ adicionándoles por la libre toda clase de pormenores que ellos no consultan, hasta acabar con una reflexión contradictoria acerca de la "esterilidad" de la poeta, a la que primero califica de "voluntaria" y después presume biológica. Comparénse esta dos citas: "En Gabriela Mistral, la musa fue la tragedia de sus amores, seguida del voto de muerte mundanal, de muerte sexual; un enclaustramiento laico sin claustro; $y$, por consiguiente, la esterilidad voluntaria y ofrecida en homenaje de amor al muerto, la maternidad fracasada, lo que en una mujer bien mujer equivale a la vida entera frustrada". Eso de un lado, y del otro: "¿Quién no las ha visto, inconsolables, ilusas, terribles de empecinamiento, hacer antesala en las oficinas de todos los ginecólogos? ¿Esperar, con fe redoblada, de manos de éste la concepción que no les dio el médico anterior? ¿Entregar su cuerpo a las más inconcebibles pruebas, como en el éxtasis de un sagrado rito?". Julio Saavedra Molina. "Gabriela Mistral. Su vida y su obra”, prólogo a Poesías completas (Madrid: Aguilar, 1958) XXXVIII y LXXI-LXXII. Todo esto hasta el golpe de gracia que Margot Arce le asestó a la cátedra en 1957, al sugerir que bien pudiera ser que haya habido (¡horror de horrores!) más de un amor en la vida de Mistral.

${ }^{2}$ Gaston von dem Bussche. Visión de una poesía (Santiago de Chile: Ediciones de los Anales de la Universidad de Chile, 1957) 16.

${ }^{3}$ Jorge Guzmán. "Gabriela Mistral: 'por hambre de su carne”" en Diferencias latinoamericanas (Mistral, Carpentier, Garcia Márquez, Puig) (Santiago de Chile: Centro de Estudios Humanísticos. Facultad de Ciencias Físicas y Matemáticas. Universidad de Chile, 1985) 23. 
Por lo que a mí respecta, lo primero que voy a decir es que no siento que "Los sonetos de la muerte" sean tres textos, sino uno, por lo que a la consideración aislada de cualquiera de sus tramos he preferido oponer en lo que viene un análisis de aspiración totalizante. En segundo término, en lo que toca a la historia de esta totalidad, ni la publicación de un cuarto y un quinto sonetos en 1983, en un libro que editó von dem Bussche, ni el juicio de Roque Esteban Scarpa, quien aboga en favor de la existencia de una serie compuesta de doce unidades, me quitan el sueño. Con el respeto debido a la erudición de ambos mistralianos, la verdad es que los sonetos que ellos acoplan a los que ya conocíamos no sólo no están a la altura de los tres anteriores, sino que hasta se diría que fueron escritos por otra persona. Por último, debo advertir que la exégesis canónica "Los sonetos de la muerte", que quiere extraer de esta obra de Gabriela un paradigma omnicomprensivo para el consumo de su poesía, basado en la secuencia pérdida del amante, superación de esa pérdida en el afecto y en la devoción por los débiles del mundo, en particular los niños, y plasmación de la nueva actitud en las sublimaciones de una lengua poética legible y servil, a mí no me resulta ni convincente ni amable. Es más: a esa exégesis yo le atribuyo una alta cuota de responsabilidad en la manufactura de la empalagosa reputación que persiguió a Gabriela Mistral durante un cuarto de siglo, y que hizo que para la gente de mi generación, esto es, para quienes éramos todavía unos barbilampiños aprendices de escritores a principios de la década del sesenta, ella se viera muy disminuida al lado de las soberbias transgresiones de un Neruda y hasta de las no tan soberbias de un Nicanor Parra. Frente al díscolo lenguaje de esos dos poetas hombres ( $\mathrm{y}$ aun frente a los lenguajes también rebeldes de un Huidobro o de un de Rokha), Gabriela se nos figuraba por aquellos años una señora cuyo mojigato discurso bien poco tenía que ver con la necesidad de cambiar las reglas del mundo en el que a nosotros nos había tocado vivir.

Es cierto que explícitamente en el primero de "Los sonetos ..." la amante se trueca en la madre. El gesto que en los versos uno y dos y cinco, seis, siete y ocho traslada los restos del amante muerto desde el nicho "helado", en el que "los hombres" lo pusieron, a la tierra "humilde y soleada", en la que ella lo pondrá próximamente, no difiere del que después dibujan los poemas de la primera sección de Ternura, cada uno de los cuales también "baja" a un niño hasta su cuna, y que son, y no por casualidad, el grupo más extenso de aquel libro. De ahí que se haya dicho no sin cierta justicia que en "Los sonetos de la muerte" la hablante "infantilizes the lover" y que el ritmo de los versos, "despite its classical form, sounds very much like that of a canción de cuna". " No sólo eso, sino que el mismo ademán reaparece en un segundo y curioso contexto. Me refiero a la imagen a la vez antigonesca y mariana de la mujer que "recibe" al Cristo crucificado en sus brazos en el "Nocturno del descendimiento", presumiblemente también con el propósito de "acunarlo" durante su último sueño. Pero, en vez de acomodar todo esto en una lectura que convierte el "ansia insatisfecha de maternidad" en una motivación "cardinal" de Gabriela, según el célebre decir de Federico de Onís, ${ }^{5}$ yo quisiera explorar aquí ciertos derroteros que discrepan

\footnotetext{
${ }^{4}$ Irene Mathews. "Woman as Myth: The 'Case' of Gabriela Mistral”. Bulletin of Hispanic Studies $67 / 1(1990) 61$.

${ }^{5}$ Véase su presentación de Mistral en Antología de la poesía española e hispanoamericana (18821932) editor Federico de Onís (Madrid: Junta para Ampliación de Estudios e Investigaciones Científicas. Centro de Estudios Históricos, 1934) 921.
} 
de semejante juicio decidida y firmemente. Gabriela Mistral maestra, Gabriela Mistral mística laica, Gabriela Mistral poeta de Chile y de América o Gabriela Mistral amante y madre frustrada son los cinco paradigmas exegéticos que deseo evitar a cualquier precio.

Para volver ahora sobre la dimensión histórica de "Los sonetos ...", como dije más arriba, mi opinión es que ellos forman un texto único. Ese texto único, según acontece de ordinario en los poemas largos, cuenta una anédcdota y esa anécdota, cuya existencia los críticos tradicionales percibieron correctamente pero abordaron mediante el abuso del atajo biográfico, debiera hacernos pensar con mejores razones en los mecanismos que en el poema regulan el despliegue de la narratividad. Ahora bien, al abocarme yo a la discusión de este punto quisiera escoger como hilo conductor de mi trabajo dos detalles. El primero es que el sjuzet de la historia que cuenta el poema de Gabriela no sólo modifica, sino que invierte la cronología de sucesos que ocurrieron o que van a ocurrir de acuerdo con un orden que existe al margen de las voluntad de los participantes. El segundo es que esa cronología está dotada de un peso que excede al de una simple voluntad serializadora.

Por escueta que sea, cualquier revisión de los verbos de "Los sonetos de la muerte" tendrá que llegar a la conclusión de que sus tiempos principales son el pasado y el futuro. El presente de los versos treinta y tres a treinta y nueve en la tercera unidad, es, desde luego, un falso presente. Trátase alli de un discurso narrativo directo o, si se prefiere, de un "presente histórico", es decir, de un pasado que se articula en presente pero sólo con el propósito de darle, como señala Bello en su Gramática, "más viveza" a los recuerdos. ${ }^{6}$ Además, el "dejara" del verso treinta es mucho menos un imperfecto de subjuntivo, que encubre a un pluscuamperfecto de indicativo, según un uso que deriva del latín y que Lapesa nos asegura que era viejo ya en el siglo $\mathrm{XVI}^{7}$ (aunque haya vuelto a ponerse de moda en el siglo XIX cuando "lo reavivaron los escritores románticos"8), que una perversión todavía peor, por lo general lamentada hasta las lágrimas por los gramáticos de temperamento castizo, y que es la del imperfecto de subjuntivo con función de pretérito de indefinido.

Esto significa que los únicos verbos del poema en presente verdadero son los de las dos líneas finales: "¿Que no sé del amor, que no tuve piedad? / ¡Tú, que vas a juzgarme, lo comprendes, Señor!". No cabe duda de que al llegar a esas dos líneas el poema largo de Mistral pliega las alas sobre la actualidad de su enunciación, así como sobre la relación entre esa actualidad enunciativa y la actualidad receptiva del lector implícito. En rigor, ese es un presente que había estado en ese mismo lugar desde siempre, como el tiempo no expreso de la enunciación, como el intervalo (y ésta es su verdad profunda) en el que se ins/escribe la poesía.

Con lo que va quedando claro que la historia de "Los sonetos de la muerte" combina cuatro pasados, un presente y tres futuros, si prescindimos de subdivisiones menores que son igualmente posibles y que aumentarían la cifra total más aún - a cinco pasados y

\footnotetext{
${ }^{6}$ Andrés Bello. Gramática de la lengua castellana destinada al uso de los americanos en Obras completas, Vol. IV (Caracas: Ministerio de Educación, 1951) 197.

${ }^{7}$ Rafael Lapesa. Historia de la lengua española, $9^{\mathrm{a}}$ edición (Madrid: Gredos, 1981) 403-404.

${ }^{8}$ Charles E. Kany. Sintaxis hispanoamericana. Traducido por Martín Blanco Alcarez (Madrid: Gredos, 1969) 209.
} 
cuatro futuros, de no ser erróneo mi cálculo. Por estos varios tiempos se deslizan las diversas escenas del melodrama amoroso que monta Gabriela en este texto, aunque no en ese orden, pues en la disposición del sjuzet es fácil comprobar que los tiempos se mueven desde el futuro más cercano al más lejano, y desde el pasado más lejano al más cercano. En lenguaje gramatical y sumario, prescindiendo por consiguiente de las catálisis y limitándonos al encadenamiento de los núcleos narrativos tan sólo, pudiéramos decir que los verbos se suceden en el sjuzet de "Los sonetos de la muerte" desde el futuro simple al futuro anterior al pasado anterior y al pasado simple, para rematar en un presente simple, que tiene que ser el de la enunciación del discurso. Creo que si tenemos esto en cuenta podremos reconstruir la anécdota que el poema relata en toda su complejidad, sin hacer uso (y abuso) de la historia personal de la poeta; además, debiera sernos posible cotejar esa anécdota con su semiosis de lectura y derivando de ello las conclusiones que nos parezcan pertinentes.

Como sabemos, el orden cronológico de los acontecimientos que el poema relata comienza con una visión paradisíaca, cuando la vida del amante (y suponemos que también la de ella) "en gozo florecía". Esto hasta que "malas manos" se hicieron cargo de esa vida, la "tomaron", "entraron" en su clausurada pureza, y por ello él abandonó "su plantel nevado de azucenas". En vista de lo ocurrido, y haciendo uso de una tautología que es tan escandalosa como conmovedora, ella le pidió a Dios que o lo "arrancaba" de esas "manos fatales" o lo "segaba en flor". De entre estas alternativas, Dios escoge la segunda, por lo que no tarda en detener(se) "la barca rosa" del vivir de él. Pasamos luego al futuro, en el que ella lo "bajará" desde su cárcel artificial, "el nicho helado" donde los hombres "lo pusieron", para instalarlo en una cárcel natural, "la tierra humilde y soleada" (no bromeo, la tumba en la que ella se apresta a depositarlo es también literalmente un sitio de encierro, en el cual, después de ser espolvoreados con "tierra y polvo de rosas", "en la azulada y leve polvareda de luna, / los despojos livianos irán quedando presos"); en un futuro más lejano todavía, ella perecerá también y será descendida hasta la "quieta ciudad", donde se reunirá con él, le hablará y le revelará por fin el misterio de lo acontecido en un tiempo que para entonces se habrá hecho remoto y desprovisto de su anterior patetismo, todo ello mientras los amantes se disponen a yacer el uno junto al otro "por una eternidad". En el sjuzet, en cambio, los siete tiempos que no son el presente funcionan más bien como una especie de embudo, con las instancias perfectas en la mitad del discurso y las imperfectas por las orillas. Es decir que el derrame de la narración mistraliana sobre la página blanca se inaugura con el proyecto de mudar el cadáver de sitio y desde allí se moviliza hasta el futuro en el que ambos estarán, al tiempo que unidos, absortos en los altibajos de una gran charla post mortem. Luego el relato se reabre con un segundo estadio absoluto, el de la temporada del gozo, prolongándose esta vez hasta la desaparición de él. El discurso poético se clausura con la coda en presente ya aludida.

¿Qué podemos inferir nosotros a partir de aquí? Por lo pronto, yo argumentaría que la recomposición del tiempo de la historia por el tiempo del sjuzet le infunde a los hechos narrados en el poema de Gabriela una significación que no es la de ellos solamente - si es que los hechos en bruto poseen una significación que les sea propia y no son más bien una muestra de la vacuidad del universo, proposición con la que coquetea Jonathan Culler en 
su artículo sobre los análisis que seleccionan un procedimiento de trabajo similar al nuestro.' En todo caso, y para explorar el asunto que aquí nos preocupa con la ayuda de una perífrasis prestigiosa, si por ejemplo la totalidad del relato de Mistral traspone los cinco tiempos del ciclo cosmogónico judeo-cristiano, a saber, el paraíso (la vida en el gozo), la expulsión del paraíso (el abandono del plantel de azucenas y la muerte misma de él), la vida en el dolor (la actual de ella) y en la fe (la certeza de que como premio a su sufrimiento volverá a verlo y a hablarle después de su propia muerte), para acabar en el clímax que es la ganancia de la eternidad (la reunión en el gozo de nuevo), cada uno de tales núcleos con sus posibles catálisis, según quedó dicho más arriba, su recomposición en el sjuzet, que inyecta los tiempos absolutos en el centro del discurso, lo que hace es nada menos que desencajarlos de su con-secuencialidad arquetípica. El comienzo de la historia consiste ahora en el traslado de los "despojos" y el fin de la misma en la constitución originaria de tales despojos, es decir, en la muerte prematura de él. En el centro del discurso, en cambio, esto es, "en el interior del sepulcro en que el texto deviene al cabo de las varias maniobras de trasvasije que su autora ejecuta" (y maniobras que hacen del texto el proscenio ideal para una tragedia folletinesca, dicho sea de paso), quedan enterrados los tiempos de la perfección nostálgica y la perfección utópica. Ahí, en el medio y abajo, reside la dicha; en las orillas y arriba, la miserable certidumbre de la condena existencial.

Por otra parte, tampoco cuesta descubrir en esta reordenación de los signos en el sjuzet una suerte de reescritura cristiana de la estrategia metapoética modernista, la que representa hasta con la disposición de las grafias en la página su confianza en una salida intima y/o artística frente a la irreparable pobreza de la historia, algo que puede comprobarse en las obras respectivas de Darío y Rodó. En ellos, el discurso de la literatura se jacta también de poseer un doble fondo. La especulación dariana en torno al contraste entre "harmonía verbal" y "melodía ideal", derivada del musicalismo de los simbolistas franceses y que encontramos enfáticamente expuesta en el párrafo cuarto de las "Palabras liminares" de Prosas profanas, o la quimera de un "reino interior", en el poema del mismo nombre en ese libro así como en el Ariel de Rodó, no son más que manifestaciones subsidiarias del planteo en el que ahora estamos incidiendo. Pero por de contado se da que Gabriela no repite a los modernistas, en cualquier caso que "sus intuiciones más profundas" no los repiten, y que aproximarnos a "Los sonetos ..." como si se tratara únicamente de una reescritura alegórica del mito cristiano tampoco nos ayuda a entender la transformación del tiempo de la historia en/por el tiempo del sjuzet.

A mi juicio, existen tres respuestas más o menos válidas para esta pregunta, que parece ser la que corta las aguas en cualquier exégesis de "Los sonetos de la muerte": una standard, otra que podríamos denominar técnico-narrativa o narratológica, cuya gran limitación es el formalismo, y una tercera, que es la que a mí me interesa más y que tratará de leer los signos del texto mistraliano poniendo el acento en sus connotaciones sexuales. Para la primera y tercera soluciones, el emplazamiento del absoluto de la existencia en el centro del discurso deviene en un sine qua non hermenéutico, si hemos de aceptar que él textualiza el emplazamiento de un absoluto existencial, de algún absoluto existencial, en

\footnotetext{
9 Jonathan Culler. "Fabula and Sjuzet in the Analysis of Narrative. Some American Discussions". Poetics Today 3 (1980) 28-29.
} 
el más allá de la conciencia. Salvados de un salto los espacios que los separaban, el principio y el fin de la historia individual y el principio y el fin de la historia social se reunirían así en un solo tiempo de stasis cuyo albergue propicio (habida cuenta de la miseria del mundo) es el "hondor recóndito" del espíritu, la zona lunar de la conciencia. La segunda solución, en cambio, ignora ese salto y arguye que al segundo soneto sigue cronológica y lógicamente el tercero, que entre ambos no hay inconexiones, que el discurso disfruta de una perfecta continuidad.

Frente al emplazamiento del absoluto existencial en el centro del poema, la exégesis standard no se detiene ni un minuto. He aquí, nos dice, y es lo que hemos oído y leído mil veces, a una mujer que se ha visto despojada, por la desaparición de su hombre (por su suicidio: el suicidio del estafetero Ureta, ya sabemos que no hay mediaciones ni distancia para este punto de mira entre la realidad biográfica y la realidad del texto), de la posibilidad de llegar a ser lo que toda mujer quiere ser: esposa y madre. Habiéndole robado la malevolencia del hado el acceso a la perfección femenina, a esa clase de perfección femenina, y que por cierto es la única concebible de acuerdo con los prejuicios sexistas de la perspectiva de marras, Gabriela Mistral empuja su frustración hacia atrás y hacia adentro, enterrándola allí por todos los años que le restan de vida, pero no sin cavar al mismo tiempo en su conciencia la grieta por donde se le escurrirá poco después el amor por los niños y/en la escritura pueril. La teoría del "ansia insatisfecha de maternidad", la de Federico de Onís, como estímulo y razón de su obra, queda así demostrada.

El narratólogo observará, por su parte, que en el verso primero del tercer soneto, el que inaugura la irrupción del pasado en el texto, la mujer se sigue dirigiendo a su amante: "Malas manos tomaron $t u$ vida", le recuerda solemnemente. No sería, por lo tanto, ilegítimo suponer que lo que ocurre en esa última de las tres unidades del poema, y por lo tanto todo lo que va en tiempo pasado, es un episodio que retoma en otro nivel el modelo comunicativo que se había mantenido en vigencia hasta el momento anterior, así como también el hilo de los episodios que se narran en las dos unidades que preceden a esa. Por medio de una elipsis, la del marco en futuro, y de una narración que adopta por ese mismo motivo el presente que según sabemos corresponde al estilo directo, $y$ que de hecho va entrecomillada en el discurso, en el tercer soneto la hablante estaría llevando a cabo el proyecto cuya realización adelantara en la conclusión del soneto dos, es decir, le estaría contando a él lo que entonces pasó o le pasó: "el por qué, no madura / para las hondas huesas tu carne todavía, / tuviste que bajar, sin fatiga, a dormir". El tiempo del tercer soneto deja pues de ser, para esta segunda modalidad de análisis, un tiempo "histórico" en sentido estricto, y pasa a ser un tiempo que visionariamente prefigura los efectos del ánimo profético del cual se dieron toda clase de muestras en los dos capítulos previos, cerrando de tal manera el ciclo que cubre desde el presente de la enunciación hasta el comienzo de una plática que, como en la novela de Rulfo, tiene lugar en el cementerio y después de la muerte de ella.

No puede negarse que de este análisis se desprenden algunos datos que son aprovechables en el contexto del nuestro, pero siempre que tengamos el buen tino de separar la paja del trigo. Porque la consideración que en mi criterio debiera preceder a todas las demás en un abordaje actual de "Los sonetos de la muerte", ya que de eso se trata al fin y al cabo, es la que observa que la mujer que habla en ellos no pierde a su amante, al hombre muerto, por obra del azar o de la (mala) voluntad del mundo, sino que, muy por el 
contrario, es ella la que desea y causa su muerte. Guzmán tiene por lo tanto razón cuando asegura que la imagen modélica de esta poesía es la de "una mujer que deseó y celebra la muerte de su amado", aunque después no le saque a esa hipótesis todo el partido que le pudo sacar. ${ }^{10}$ También tiene razón Hernán Silva, si bien desde un punto de vista que se halla en las antípodas del de Guzmán. Sostiene Silva, quien considera que el principio que otorga su coherencia a Desolación es la oposición cristiana entre el alma y el cuerpo, que, al querer el alma elevar el cuerpo hasta su sitio, descubre que "esta fusión, aunque se puede dar en ciertos momentos excepcionales, mientras el cuerpo esté vivo nunca puede ser duradera ... Tan sólo con la muerte del cuerpo, con la muerte de los instintos se puede lograr una unidad permanente. Por eso la apasionada mujer de 'Los sonetos de la muerte' aspira unirse a su amado en la sepultura y realizar el amor puro y eterno con que soñaba su alma"." El efecto es, por cierto, el mismo en ambos casos. Al alma le hace falta la muerte del cuerpo tanto como a la amante le hace falta la muerte del amado. Cualquiera sea el esquema interpretativo que uno le calce al discurso, no cabe duda de que la hablante del poema de Gabriela alza su plegaria hacia Dios, que le cuenta a Éste su cuita y que le exige que intervenga ejecutivamente en el desastre ocasionado por la aparición de la sierpe fatídica en el paraíso del gozo, con una actitud que Mistral va a reiterar en otros poemas que no comparten la motivación de los que se inspiran en el affair Ureta, como afirmaba en 1957 y haciendo gala de una clarividencia que el conocimiento de las cartas de amor ha venido a confirmar años más tarde, Margot Arce de Vázquez. Muy diferente es que a la mayoría de los comentaristas de "Los sonetos ..." esa propuesta narrativa no les haya parecido tolerable y (por lo mismo) "verosímil", en el sentido que Genette le da a esta palabra, o "legible", como hubiera dicho Barthes, y que por eso hayan preferido reemplazarla con la verdad biográfica, haciendo uso de un ardid extracurricular, el que, si bien desbordaba los principios de una ética del intérprete, era comprensible por lo tranquilizadora, puesto que al hacerse tal reemplazo la responsabilidad de la muerte corría de cuenta del muerto mismo. Ella no era así la autora de la tragedia, sino su víctima. Complaciente hasta la saciedad, esta lectura del poema de Gabriela satisface lo mismo al ideologismo romántico, el que verá en Mistral a la mujer a la que el destino le colma la copa de desdichas, pero que a pesar de eso decide arrastrar hasta la tumba el culto de su primer y malogrado amor, lo que es biográficamente falso, como reconocen aun los aficionados a dicha leyenda, que al ideologismo patriarcal, el que entiende que la mujer no puede crearse jamás su propia vida, pues la vida sólo tiene sentido a partir de una perspectiva masculina del mundo, lo que si no es falso debiera de serlo.

Pero el caso es que Gabriela cambia al poetizar el dato biográfico, cualquiera sea el sitio que éste ocupa en el desenvolvimiento de su historia personal. Además, al hacer tal mudanza genera un escenario de segundo grado en cuyo marco su poema transfiere la responsabilidad de la muerte desde él a ella. Así, si en "Los sonetos..." Dios le propina al sujeto del marras "el largo sueño" que Él sabe dar es porque la mujer que lo ama o lo amó se lo ruega. Más aun, ella le pide a Dios que le conceda ese favor porque "otras manos", manos que no son las de ella, han "entrado" a saco en el "plantel" donde la vida de él se

\footnotetext{
${ }^{10}$ Op. cit. 22.

"Hernán Silva. "La unidad poética de Desolación". Estudios Filológicos IV (1968) 163-164.
} 
hallaba protegida hasta ese instante y están haciendo ahí de las suyas. No se trata de celos, sin embargo, como pudiera creerse y como efectivamente creyeron Gastón von dem Bussche y Jorge Guzmán. Se trata más bien de cuál es el código que va a orquestar el futuro de esos dos que presumiblemente se disponen a emprender una vida en común. La ideología patriarcal dominante exige que la invención del futuro (de todo futuro) sea un privilegio masculino, pero Gabriela se niega a acatar dicha norma, de manera que él o es de ella, doblegándose ante su ley (aunque la determinación de cuál sea la índole de esa ley es un problema nada fácil de resolver), o no es de nadie. En este universo, en el que el poder y la lucha por el poder constituyen factores inescapables y sin que ello dependa para nada del esfuerzo personal de quienes participan en el juego, Foucault avant la lettre, como quien dice, no existen los términos medios. La ley de él y la ley de ella se concretan a través de discursos que se constituyen al modo de oposiciones binarias, oposiciones que devienen axiomáticamente irreconciliables porque funcionan como redes con respecto a las cuales los individuos que las sufren es nada o muy poco lo que pueden hacer. La legalidad del amante anula a la de la amada (aun estos sustantivos, que preservan el contraste actividad/pasividad, que es el propio de los participios de los que derivan, colaboran, como de costumbre, en la mantención del embrollo. Además, ¿cómo no darnos cuenta de la síntesis que en esos dos vocablos funde la actividad con el presente masculino y la pasividad con el pasado femenino? La conclusión es inevitable: la mujer no es nunca actual, no existe jamás en el hoy); la de la amada exige la eliminación del (la del) amante. Dicho con más precisión: ella, para ser, debe subvertir el código de El Padre y eso aun cuando no tenga a nadie a quien poner en el trono del poder decapitado.

Pero, ¿qué es eso que ella quiere ser? Es cuando nosotros nos atrevemos a parodiar esta vieja pregunta freudiana que nuestra indagación produce sus mejores resultados, me parece a mí. Porque no es que la mujer que habla en "Los sonetos de la muerte" pretenda reproducir el modelo de la femineidad típica. Si ese fuera su propósito, no tendría necesidad de ponerlo a él bajo tierra, dado que esa clase de femineidad ha vivido siempre en íntimo contubernio con la Ley del Padre. Peor todavía, después de los muchos progresos y de la gran capacidad de persuasión alcanzada por el pensamiento feminista durante las últimas décadas, yo creo que a casi nadie le cabrá duda de que la misma no es el fruto de la creatividad de las mujeres sino que es una de las más estupendas, si no la más estupenda, entre las operaciones de la práctica patriarcal. "Tout être humain femelle n'est donc pas nécessairement une femme; il lui faut participer à cette réalité mystérieuse et menacée $q u$ 'est la féminité", escribió hace ya casi medio siglo Simone de Beauvoir en la primera página de Le Déuxieme Sexe.

Por otro lado, aunque el universo mistraliano es dualista, ella tampoco pretende ser él. Mejor dicho, ella entiende que esa no es una posibilidad real, que el espacio masculino le está vedado, que su apropiación no es ni siquiera pensable para quienes nacieron con las señas biológicas cambiadas. No habiendo pues en el horizonte psíquico de Gabriela dónde ni cómo levantar una tercera posición, estando su vida desprovista de un "país" que tenga un "nombre", dicho sea esto con el estribillo subrayado de "País de la ausencia", es claro que lo único que le queda por hacer es reencauzar su energía libidinal, emprendiendo un continuo montaje de simulacros de él, pero de un él que ya no es él, sino, para volver sobre el esqueleto lacaniano, es El-Nombre-del-Padre. Es decir, es El Falo Supremo, es el 
Significante Trascendental, es La Voz del Maestro. Es decir, es Jerónimo Godoy Villanueva, es Ureta, es Videla Pineda, es Magallanes Moure, es Yin-Yin, es José Vasconcelos, es el presidente Aguirre Cerda, es Eugenio D'Ors, es El Rey de Suecia y es el mismísimo Dios, todos y cada uno de los hombres que ella había conocido hasta aquel entonces o que conocería a partir de aquel entonces y ninguno de ellos en particular.

Pero esos simulacros tampoco van a conformarse con ser simples reproducciones de las correspondientes ediciones princeps, sino que las van a magnificar. Ella adopta la Ley del Padre, la asume, la recrea y la exalta. Es ésta, para compararia con un texto que me parece cercano en espíritu, una coincidencia de Gabriela (y no rara) con el aprecio que por esa misma Ley manifiesta Bernarda Alba en la célebre pieza de Federico García Lorca. El resultado es el hostigoso perfil biográfico que tan bien conocemos, el de los manuales y las fotos de periódico, la maestra excelsa, la diplomática solemne, la inspiradora de buenos y nobles sentimientos. "Maestra de niños en la escuela, maestra de pueblos en el ámbito más extenso del continente entero, he allí la misión de Gabriela", escribe a propósito de esto el más rendido de todos sus áulicos. ${ }^{12}$ Personalmente, no creo que ésa sea la Gabriela en quien las feministas chilenas y latinoamericanas van a reconocer a una precursora de sus perspectivas actuales. Por el contrario, lo más seguro es que por este camino se acabe confirmando el exabrupto de Saavedra Molina, cuando aquel buen señor manifiesta la complacencia que le produce el hecho de que Gabriela haya tenido "la simpatía de no militar en el feminismo ni de pregonarlo como una reivindicación". ${ }^{13}$

Pero lo que me importa destacar en estas páginas es que esa no es toda Mistral. Más precisamente: que esa figura pública de tan cepillados perfiles no es la de la poeta Mistral. En el plano histórico, El Padre se impone y acalla a La Madre, la que o se sacraliza en la epidermis del cuerpo escriturario o retrocede hasta los rincones pre o paraverbales de la conciencia, acabando ahí, y sólo ahí, con una cierta dimensión del conflicto que Mistral arrastró a todo lo largo de su vida. En el plano poético, no sucede lo mismo, sin embargo, y no sucede porque la historia es siempre lo que queda después de la tormenta, lo que permanece lavado, neutralizado, naturalizado; al contrario de la poesía, que es el sitio mismo en el que la tormenta acaece, donde todo significa y donde todo se relaciona con todo en y desde el "vórtice" del imaginario, como comprendieron Jakobson y los formalistas rusos, como sospechó Sartre y como repiten hasta los teóricos que son más adeptos al mecano semiótico. En otras palabras, la poesía es ese discurso en el que las tensiones de las que está hecha la vida, y que la vida acabará tarde o temprano disuadiendo, se encuentran aún sin anestesiar. Poesía que en lo que toca a Mistral se carga con una intensidad que a nosotros nos pasma a causa de su abandono de La Casa de La Madre, así como debido a su invasión ilegítima de El País del Padre.

En cuanto a este segundo aspecto del dilema que peculiariza el poetizar mistraliano, creo que puede comprobarse que, no obstante el testimonio en contrario característico de los documentos y la memorabilia que exudan las publicaciones oficiales, lo cierto es que

\footnotetext{
12 Benjamín Carrión. Santa Gabriela Mistral (Ensayos) (Quito: Casa de la Cultura Ecuatoriana, 1956) 45.

${ }^{13}$ Op. cit. XV.
} 
Gabriela entró siempre en el territorio paterno con una sensación de extrañeza y que su poesía lo confiesa directa o desplazadamente. De ahí derivan tanto la comodidad que ella siente entre seres y objetos humildes, aspecto que se atrajo la aprobación de Jaime Concha, como el desasosiego que nos dan a conocer sus poemas de exilio, algunos de los más profundos y bellos que se han escrito en un continente donde esta clase de literatura no es escasa, y a los que cabe interpretar como transposiciones, por lo común merced al contraste entre Tercer y Primer Mundo, de su alienación radical en el país de El Padre. Tómense por ejemplo "La extranjera", de Tala, y "Emigrada judía", de Lagar, composiciones entre las cuales median veinte o más años pero que a pesar de eso se leen muy bien la una junto a la otra $o$ incluso la una sobre la otra. La distanciadora primera persona plural del sujeto de la enunciación y la tercera singular del sujeto del enunciado, en "La extranjera", o la primera persona singular, en "Emigrada judía", nos desconciertan al comenzar un cotejo, pero pecaríamos de ingenuos si no nos percatáramos que se trata de trucos retóricos destinados a manipular la problemática del desarraigo que obsesionaba a Mistral por los años de su madurez creadora, los mismos en que, como ha visto más de un crítico y es probable que a causa de su frecuentación de la poesía en lengua inglesa, su estética estaba entrando en una fase objetivista. Esto significa que el signo que nos importa destacar como factor clave en los dos poemas citados es el de la identidad genérica, un signo que nos está hablando en uno y otro casos de mujeres cuyos paisajes, cuya lengua, cuya vida y cuya muerte les son irremediablemente ajenos. Como de costumbre, el paraíso no es el presente chileno, el latinoamericano o el tercermundista, sino lo que se quedó en El Comienzo y cuya memoria se atesora en el fondo del pecho; el presente y el futuro, cualesquiera que ellos sean, y en todo caso el futuro que culmina con la desaparición de la hablante, tienen lugar en un espacio en el cual esas mujeres serán intrusas hasta el fin.

Para volver una vez más sobre "Los sonetos de la muerte", las interrogaciones y el apóstrofe en los últimos dos versos de la tercera unidad adquieren a la luz de lo que llevo dicho hasta este punto una transparencia impresionante: "¿Qué no sé del amor? ¿Qué no tuve piedad? / ¡Tú, que vas a juzgarme, lo comprendes, Señor!”. He ahí la culminación de la historia que Gabriela Mistral relata en este poema, al que se suele considerar como el semillero de su práctica posterior, y he ahí también la descentrada cerradura del texto. No era nuestro devaneo narratológico del todo inútil, por lo visto, ya que al insistir en la continuidad que existe entre el tú de las dos primeras unidades y el que reaparece en el primer verso de la tercera, él nos trazó una ruta de lectura, aun cuando una ruta a la que el advenimiento del verso cuarto del último soneto (o del verso treinta y dos, si estamos pensando en una totalidad indivisa) rectifica obligatoriamente. Ese verso introduce un término en el que Jakobson hubiese reconocido un shifter, uno de esos cambios de dirección del discurso que Roberto Hozven tradujo al español con el nombre de "embragues" y que alteran el "contenido material" de las formas "yo" y "tú": "Malas manos entraron trágicamente en él ...", etc. Incluso los puntos suspensivos que siguen al término que acabo de subrayar corroboran su importancia.

En esta encrucijada, puede percibirse que el progreso semiótico de "Los sonetos ..." debe optar entre uno u otro de los dos acaeceres siguientes: o la hablante muda de receptor, desde "él" a "Él" (o desde "tú" a "Tú"), mudanza que constituye la función por excelencia de los shifters jakobsonianos, o, lo que a mí me gusta mucho más, el "él/Él”, con el que 
ella se está entonces comunicando, se convierte o, mejor dicho, se revela como todos los "él", desde el hombre muerto hasta Dios nuestro "Señor", pasando por esos varios sujetos a los que nosotros nos dimos el gusto de enumerar más arriba. En otras palabras, el "él/Él" es, una vez más, El-Nombre-del-Padre, transfigurado en esta ocasión, y muy apropiadamente por cierto, en un Tribunal de Justicia ante el que la poeta viene a confesar y a defender su horrendo crimen. Con una nueva máscara, la de Dios Todopoderoso, Ése que asoma su nariz en la última línea del poema (o en vez de una nueva máscara, ¿debí escribir un nuevo significante falogocéntrico dentro de la corrida infinita que forman aquéllos en los cuales el Padre Ausente lacaniano delega su influjo?) es el verdadero receptor de la historia. Es Dios, sí, pero también es Jerónimo Godoy, es Ureta, soy yo y es el señor que lee el poema.

De manera que en esa línea, y en la bimembre anterior, "Los sonetos de la muerte" adquieren las características de un proceso judicial in situ, el que es también - no debemos pasarlo por alto - un espectáculo teatral a tablero vuelto. El melodramatismo de Gabriela se nos ofrece en ese momento con toda la ambigua magnificencia de la que ella es capaz. Para posesionarse adecuadamente de la escena la poeta todavía en formación que Gabriela es por aquellas fechas va a echarse encima un nuevo manto. No representará ahora ni a la madre solícita, ni a la viuda doliente, ni a la amante celosa. Será, en cambio, una mujer que, habiendo cometido un delito de sangre, se presenta ante El Juez, confiesa su crimen, se defiende como puede y aguarda la dura sentencia que, según prejuzga ella misma, se le debiera administrar. El verso trece del tercer soneto (o el cuarenta y uno de la totalidad del poema) insinúa su defensa y las falsas preguntas que lo constituyen dan por supuestas unas contestaciones que la favorecen convirtiéndose en el núcleo bipartito de su argumento consciente. Amó, o sea que hizo lo que hizo por el cariño que sentía por su amante, y tuvo piedad, o sea que hizo lo que hizo para salvarlo de un mal mayor. Pero si esa defensa es la que es, la que ella articula en el contenido manifiesto de su discurso y la única que puede esgrimir ante El Juez que escucha el caso y acerca de cuya legitimidad no se le pasa por la cabeza abrigar duda alguna, muy otra es la defensa que no es, la que ella no articula expresamente y no porque no exista o porque ante este Juez no sea articulable sino porque ella misma no quiere o no sabe articularla. Me refiero al alegato de una mujer que, por circunstancias en las cuales nosotros vamos a profundizar en otro sitio, mató a un hombre, mató al hombre, para cumplir con las demandas que le hacía su proyecto vital. 